\title{
STABILITY OF BREAKWATER ROUNDHEADS DURING CONSTRUCTION
}

\author{
Marcel R.A. van Gent ${ }^{1}$ and Ivo van der Werf $^{1}$
}

\begin{abstract}
The presented study focussed on issues related to the hydraulic stability during the construction of rubble mound breakwaters. During construction the temporary roundheads differ from the roundheads in the final stage. Often a submerged uncompleted part of the breakwater is present in front of the section that reached its final crest elevation. This can occur because often the breakwater is being constructed with maritime-based equipment up to a certain elevation while the upper part of the breakwater is being constructed with land-based equipment. Three-dimensional physical model tests were performed to analyse the influence of the submerged part on the stability of the emerged part. The locations incurring the most damage clearly differ. Furthermore, for some combinations of water level, wave direction and structure geometry more damage was found for structures with a submerged part, although most combinations showed that the amount of displaced stones is generally lower for the structures with a submerged part.
\end{abstract}

Keywords: rubble-mound breakwaters; roundhead; rock slopes; wave basin; construction; wave loading

\section{INTRODUCTION}

For the design of roundheads of rubble mound breakwater the stability has been studied by several authors; for rock armour e.g. Vidal et al (1991) and Matsumi et al (1994, 1996, 1998, 2000) and for concrete armour units e.g. Jensen (1984) and Maciñeira and Burcharth (2008). For the construction of rubble mound breakwaters also other issues are important. During construction the temporary roundheads differ from the roundheads in the final stage. Often, a submerged uncompleted part of the breakwater is present in front of the part that reached its final crest elevation. This can occur because often the breakwater is being constructed with maritime-based equipment up to a certain elevation while the upper part of the breakwater is being constructed with land-based equipment. This may lead to a schematised cross-section such as shown in Fig.1 (hereafter: "Temporary roundhead" refers to a roundhead in the construction phase with a submerged berm and "Completed roundhead" refers to a roundhead with a straight slope to the bottom, without submerged berm).

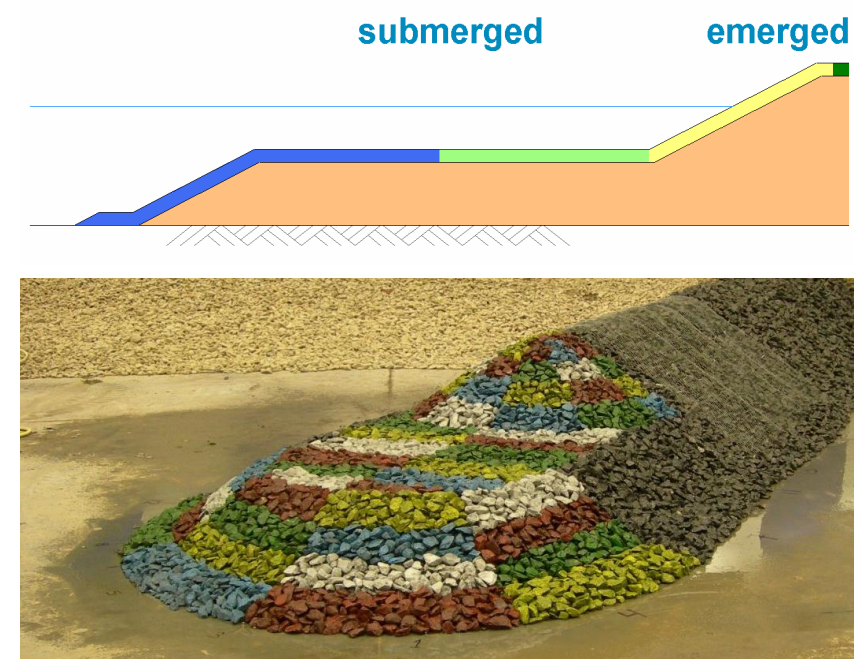

Figure 1. Schematised cross-section of a roundhead during the construction phase (upper panel) and a model of such a roundhead in a wave basin (lower panel).

For breakwaters that need more than one year of construction, such a cross-section can be present during the entire winter period if this period cannot be used for construction; the material in this cross-section needs to be stable during the storms of the winter season while in spring the construction can proceed. The uncompleted part (blue and light-green in upper panel of Fig.1) affects the wave

\footnotetext{
${ }^{1}$ Deltares | Delft Hydraulics, P.O. Box 177, 2600 MH Delft, The Netherlands, Marcel.vanGent@deltares.nl
} 
load on the roundhead (yellow in upper panel of Fig.1) and therefore affects the stability and required stone size at this temporary roundhead.

By performing a systematic test programme in a wave basin the stability of rock armour on roundheads during the construction phase is studied compared to completed roundheads. The 3D physical model tests were focussed on the stability of the emerged roundhead (yellow in upper panel of Fig.1). The stability of the roundhead, with and without the submerged part, was studied for five wave angles. The results provide information on the influence of the angle of the incident waves on rock armour stability on roundheads. For the effects of oblique wave attack on trunk sections of rubble mound breakwaters, reference is made to Wolters and Van Gent (2010).

\section{PHYSICAL MODEL TESTS}

\section{Wave basin}

The physical model tests were performed in the Delta basin of Deltares, Delft (50m times 50m). The basin has two multi-directional wave generators $(40 \mathrm{~m}$ and $26.4 \mathrm{~m}$ ), of which only the $26.4 \mathrm{~m}$ wave generator was used for the present study. To prevent reflected waves to re-reflect on the wave paddles, the wave generators are equipped with Active Reflection Compensation (all 180 paddles are equipped with this system). In the present study five wave directions were applied, all with long-crested waves. Second-order wave steering was used to generate realistic shapes of the individual waves ("Stokes waves") and realistic bound long-waves ("wave groups"). The wave board can be steered with standard and non-standard wave spectra as well as specific time series of waves. In the present study all tests were performed with a standard Jonswap wave spectrum.

\section{Structure geometries}

Structures with two slope angles were tested: 1:1.5 and 1:2. The tested structures consisted of a rock armour layer $\left(D_{n 50}=33.4 \mathrm{~mm}\right.$ for $1: 1.5$ slopes and $D_{n 50}=29.4 \mathrm{~mm}$ for $1: 2$ slopes, with $D_{n 85} / D_{n 15}$ $=1.3)$ on top of core material $\left(D_{n 50}=11.0 \mathrm{~mm}\right.$, with $\left.D_{n 85} / D_{n 15}=1.6\right)$. The thickness of the armour layers was $2 D_{n 50}$. The relative density of the applied rock was $\Delta=1.7$. The structures were positioned on a horizontal bathymetry. The crest level was $0.75 \mathrm{~m}$ above the bed. For the temporary roundheads the level of the submerged part was at $0.35 \mathrm{~m}$ above the bed. The length of the horizontal part of the submerged part was not varied (light-green in Fig.2): $1.35 \mathrm{~m}$ for the $1: 1.5$ slope and $1.55 \mathrm{~m}$ for the $1: 2$ slope. Also the width of this submerged horizontal part was not varied: $1.3 \mathrm{~m}$ for the $1: 1.5$ slope and $1.7 \mathrm{~m}$ for the 1:2 slope. The rock material was coloured to facilitate visual observations.

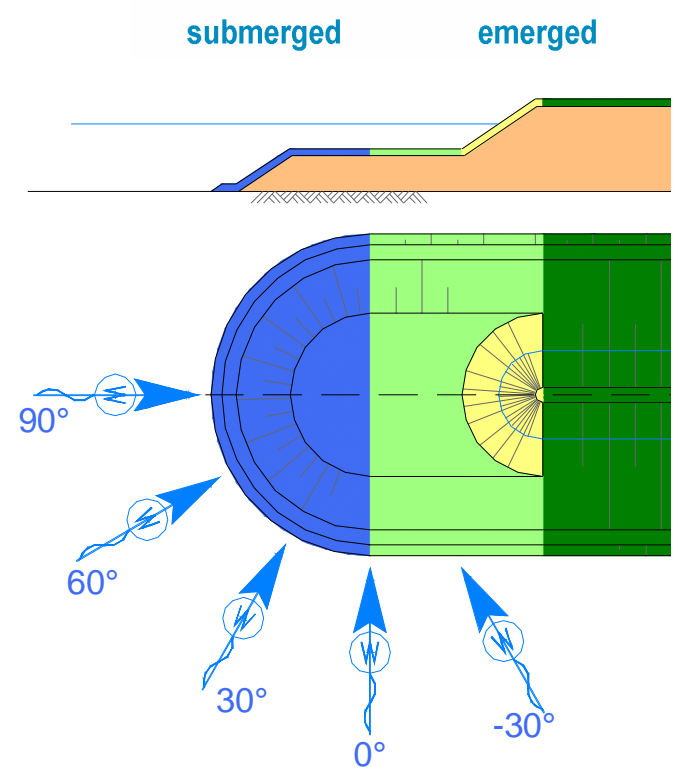

Figure 2. Schematised lay-out of a tested cross-section (upper) and top view (lower) of a roundhead during the construction phase. 


\section{Test set-up}

Two series of tests with different test set-ups were used. Fig.3 shows these test set-ups. For the wave directions $-30^{\circ}, 0^{\circ}$ and $30^{\circ}$ four roundheads were tested simultaneously (from left to right in the left panel of Fig.3): a 1:1.5 completed roundhead (blue in left panel of Fig.3), a 1:1.5 temporary roundhead, a 1:2 temporary roundhead, and a 1:2 completed roundhead. For the wave directions $0^{\circ}$, $30^{\circ}, 60^{\circ}$ and $90^{\circ}$ two roundheads were tested (panel to the right of Fig.3): a 1:1.5 completed roundhead and a 1:1.5 temporary roundhead. The walls at both sides of the basin were used to obtain the appropriate waves at the structure. At the rear side of the basin a gravel beach was used for passive wave damping while the wave generator is equipped with active wave absorption.
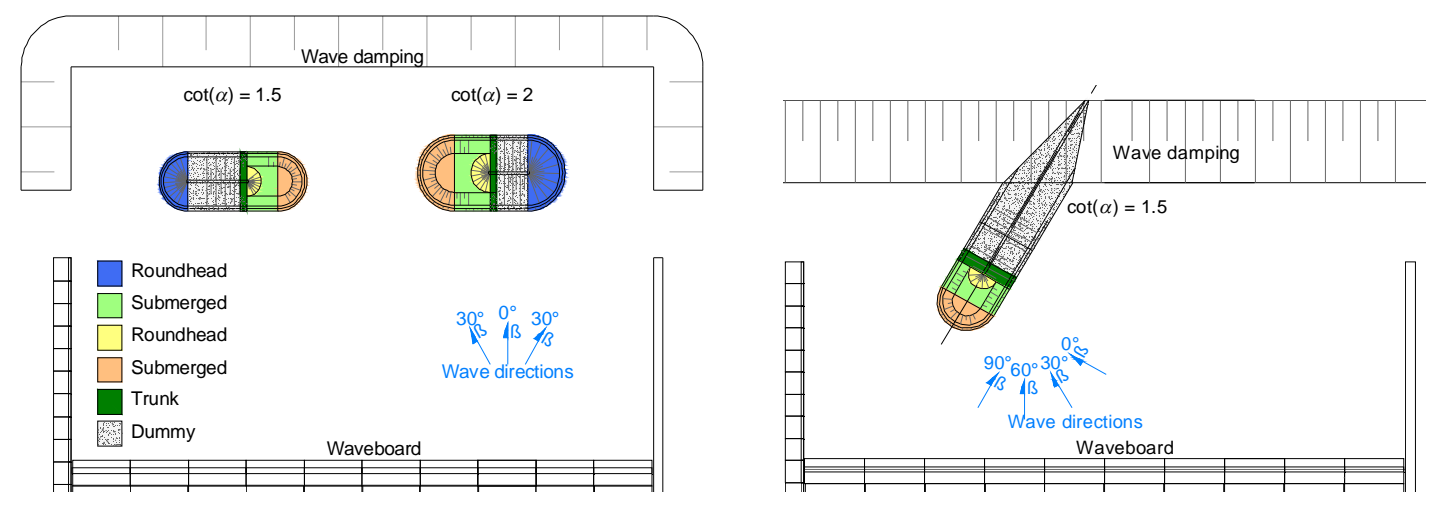

Figure 3. Test set-up for wave directions $-30^{\circ}, 0^{\circ}$ and $30^{\circ}(1: 1.5$ and $1: 2$ slopes) in the panel to the left and for wave directions $0^{\circ}, 30^{\circ}, 60^{\circ}$ and $90^{\circ}(1: 1.5$ slope $)$ in the panel to the right.

\section{Test programme}

Each test consisted of a wave train of approximately 1000 waves. During each test series the wave height was increased per test while in each test the wave steepness was kept the same $\left(s_{p}=0.025\right.$ in all tests). The wave height was increased in steps up to a level at which severe damage occurred (wave heights were between $H_{s}=0.05 \mathrm{~m}$ and $H_{s}=0.14 \mathrm{~m}$ ). Within each test series the armour layer was not repaired. The water level was varied $(0.4 \mathrm{~m}, 0.475 \mathrm{~m}$ and $0.55 \mathrm{~m})$ such that the water depth above the submerged part was $0.05 \mathrm{~m} 0.125 \mathrm{~m}$ and $0.2 \mathrm{~m}$ respectively. The test programme consisted of five wave directions.

\begin{tabular}{|}
\hline \multicolumn{5}{|c|}{$\begin{array}{l}\text { Table 1. Tested combinations of slope angle, water level and } \\
\text { wave direction. }\end{array}$} \\
\hline \multirow{2}{*}{$\cot \alpha$} & Water depth above submerged part & \multirow{2}{*}{$\beta\left(^{\circ}\right)$} \\
\cline { 2 - 4 } & $0.050 \mathrm{~m}$ & $0.125 \mathrm{~m}$ & $0.200 \mathrm{~m}$ & \\
\hline 1.5 & - & $\mathrm{x}$ & $(\mathrm{x})$ & -30 \\
1.5 & $\mathrm{x}$ & $\mathrm{x}$ & $\mathrm{x}$ & 0 \\
1.5 & $\mathrm{x}$ & $\mathrm{x}$ & $\mathrm{x}$ & 30 \\
1.5 & $\mathrm{x}$ & $\mathrm{x}$ & $\mathrm{x}$ & 60 \\
1.5 & $\mathrm{x}$ & $\mathrm{x}$ & $\mathrm{x}$ & 90 \\
\hline 2 & $(\mathrm{x})$ & $\mathrm{x}$ & - & -30 \\
2 & $\mathrm{x}$ & $\mathrm{x}$ & $\mathrm{x}$ & 0 \\
2 & - & $\mathrm{x}$ & $(\mathrm{x})$ & 30 \\
\hline
\end{tabular}

Table 1 shows, denoted by " $x$ ", the tested combinations of slope angle, water level and wave direction for the temporary roundheads. All combinations, except the three denoted by " $(x)$ " in Table 1 and including those denoted by "(-)", have been tested also with a completed roundhead. In total 21 test series were performed with a completed roundhead (see panel to the left of Fig.4) and 21 test series were performed with a temporary roundhead (see panel to the right of Fig.4). Each test series consisted of four to nine test runs with increasing wave height. The total number of tested combinations of wave height, water level, wave direction and structure geometry is 210 . 

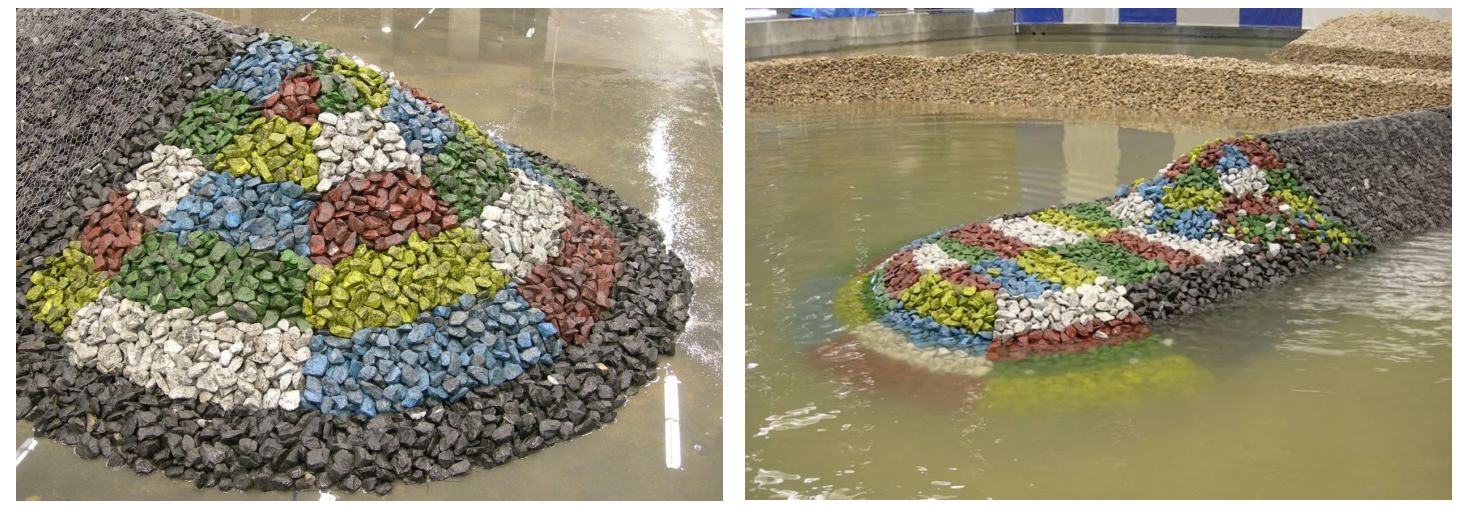

Figure 4. Pictures of breakwater roundheads; Left: 1:1.5 completed roundhead, Right: 1:1.5 temporary roundhead (water level in this picture is lower than during the tests).

\section{Damage analysis}

Damage was recorded by using pictures before and after each test to identify stones that were displaced more than one diameter (camera overlay technique). Damage will be presented as the ratio of the number of displaced stones and the total number of stones in the armour layer: $N_{d}$. Damage was measured and analysed for four segments of $45^{\circ}$ in the roundhead, see Fig.5.
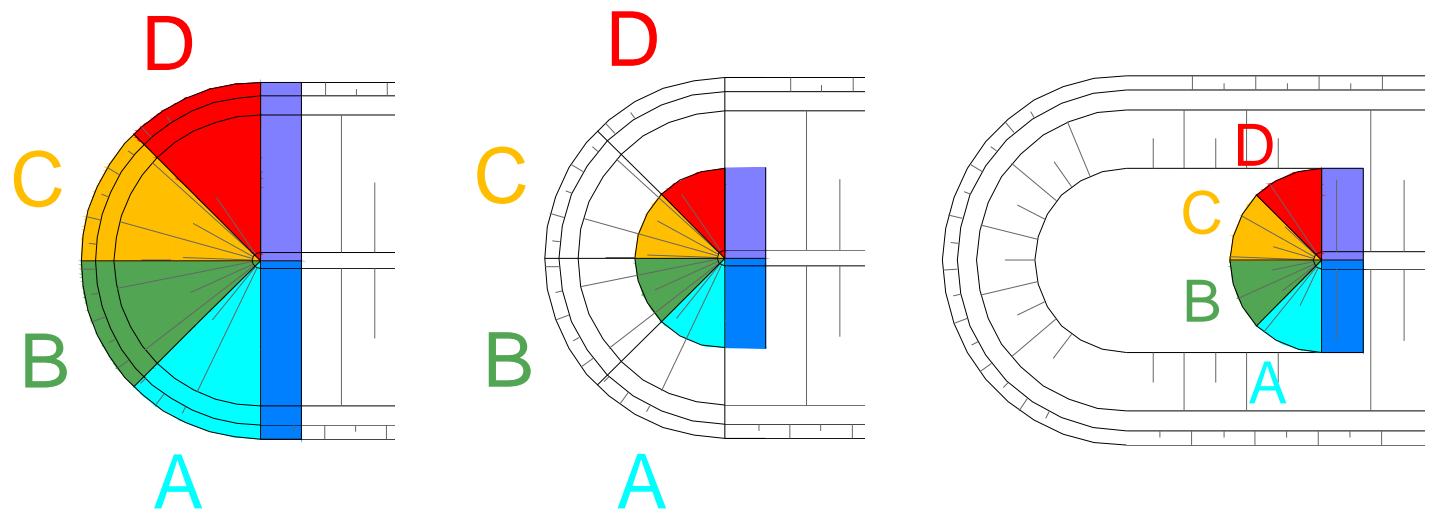

Figure 5. Roundhead segments for a completed roundhead (left and mid panel) and a temporary roundhead (right panel).

For the analysis of the completed roundhead two methods have been applied. The first was based on the damage of the entire slope (toe to crest, see panel to the left in Fig.5) and the second was based on the damage that occurred above the level of the submerged part that was applied for the temporary roundhead (berm level to crest, see mid panel in Fig.5). Fig.6 shows cross-sections of the two methods; it is indicated which part of the roundhead is used (in blue) for comparison with the temporary roundhead and which parts have not been used (in red) in the analysis.
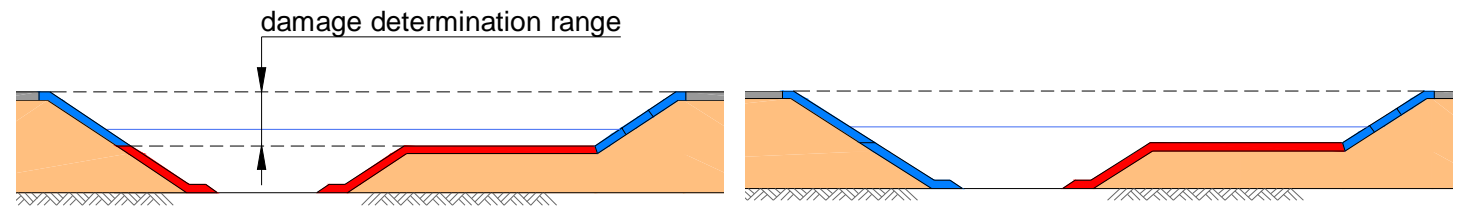

Figure 6. Two methods for comparison of damage. 


\section{TEST RESULTS}

\section{Completed roundheads (without submerged part)}

Fig.7 shows results for the 1:1.5 completed roundhead. The results shown in Fig.7 are for a water depth of $0.475 \mathrm{~m}$ (i.e. mid-water level). Each panel in Fig.7 shows the damage $\left(N_{d}\right)$ per segment (horizontal axis) for one of the tested wave directions $\left(-30^{\circ}, 0^{\circ}, 30^{\circ}, 60^{\circ}\right.$ and $\left.90^{\circ}\right)$. In each panel results are given for three to four wave heights (data points belonging to the same test/wave height are connected).
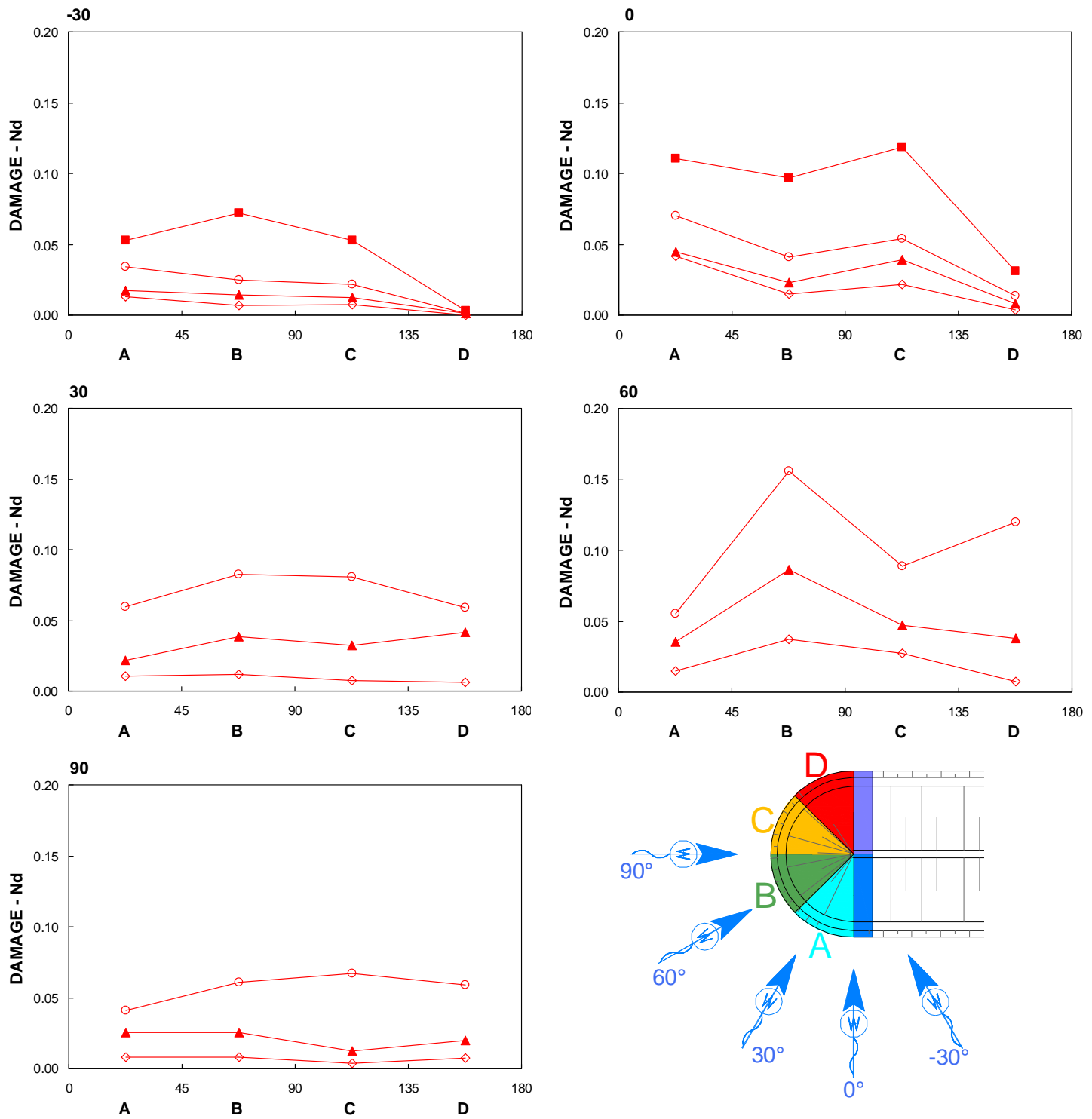

Figure 7. Damage per segment (A-D) for various wave directions $\left(-30^{\circ}, 0^{\circ}, 30^{\circ}, 60^{\circ}\right.$ and $\left.90^{\circ}\right)$ for a $1: 1.5$ completed roundhead.

Fig. 7 shows that damage is, as expected, not distributed evenly over the segments. For some wave directions more damage is observed where the angle between the wave direction and the position of maximum damage is larger than $90^{\circ}$. An angle larger than $90^{\circ}$ means that the slope is in fact a downward slope compared to the angle of wave propagation. This means that the resistance to wave loading is relatively low at such a position. For wave directions $-30^{\circ}$ (Segment B), $0^{\circ}$ (Segment C), and $60^{\circ}$ (Segment D) the position with an angle larger than $90^{\circ}$ relative to the waves indeed shows a relatively high damage level (angle between waves and position with more damage). This agrees rather well with observations by Jensen (1984) for Tetrapods where the maximum damage was 
observed at an angle of $135^{\circ}$ from the incident wave direction. Thus, Jensen (1984) also observed higher damage levels on a "rear-side segment" of the roundhead. However, in the present tests this angle is somewhat smaller than $135^{\circ}$ (in the present tests $113^{\circ}$ ). The results do not only show a higher damage level at this position with a relatively low resistance, the results also show more damage at positions with maximum wave loading, namely the segment at the front (i.e. $0^{\circ}$ relative to the direction of wave propagation). For wave directions $0^{\circ}$ (Segment A) and $60^{\circ}$ (Segment B) the results clearly show more damage at the segments that are hit first by waves (i.e. $0^{\circ}$ relative to the direction of wave propagation). For the tests with head-on-waves, i.e. $90^{\circ}$, a symmetric damage would be expected with a maximum damage in Segments B and C. The results show somewhat more damage in Segments B and C for the test with the highest waves but the results are not symmetric. This is expected to be caused by variations of stones in the armour layer, not by variations in the wave loading.

Summarising, the results indicate that there are two segments with relatively high damage levels, namely the "front segment" (i.e., the segment with maximum wave loading; $0^{\circ}$ relative to the wave direction) and a "rear-side segment" (i.e., a segment with relatively low resistance) starting at an angle of $90^{\circ}$ relative to the wave direction.
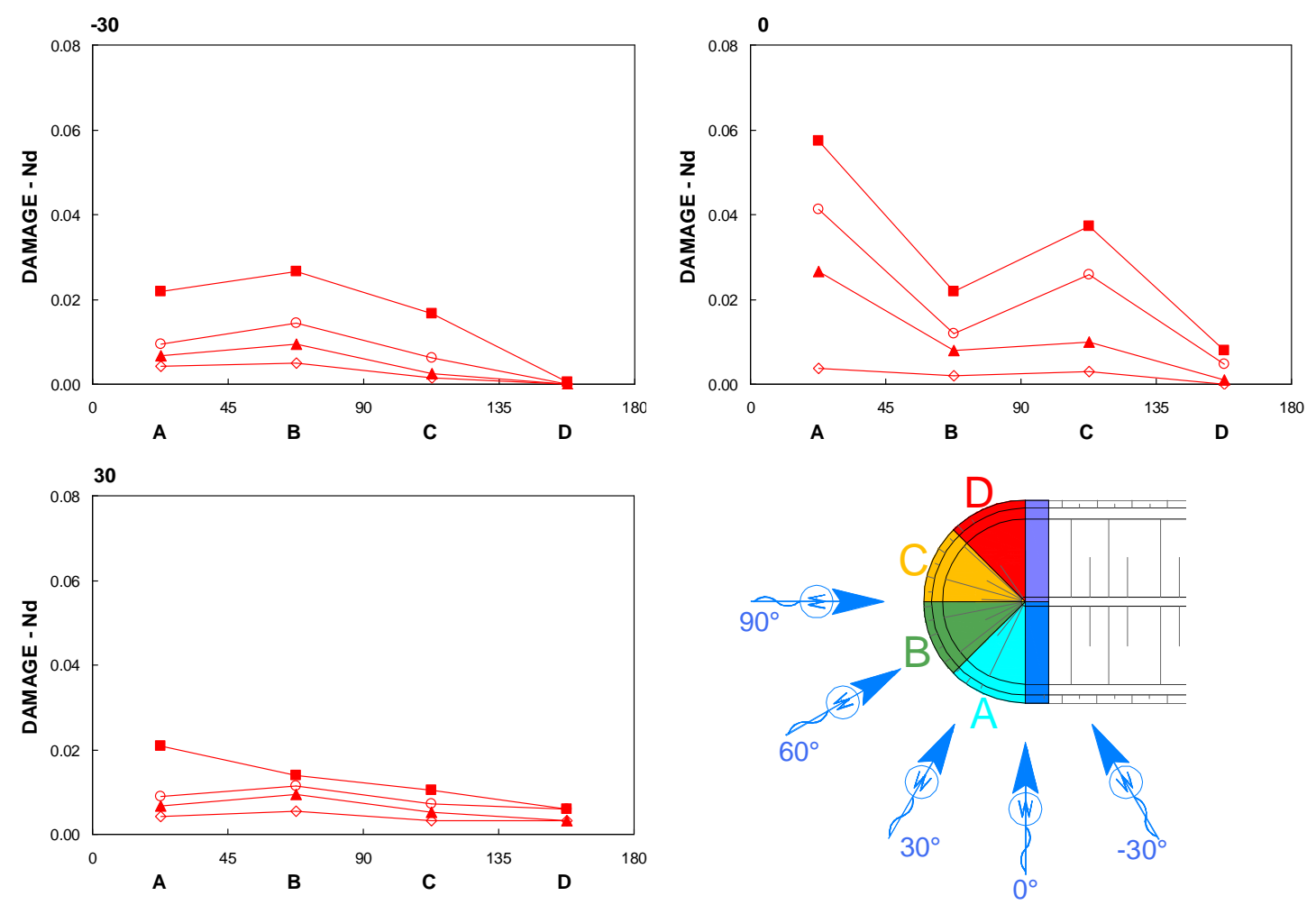

Figure 8. Damage per segment (A-D) for various wave directions $\left(-30^{\circ}, 0^{\circ}\right.$ and $\left.30^{\circ}\right)$ for a $1: 2$ completed roundhead.

Fig. 8 shows results for the 1:2 completed roundhead. For each of the tested wave directions $\left(-30^{\circ}\right.$, $0^{\circ}$ and $30^{\circ}$ ) results are shown for a water depth of $0.475 \mathrm{~m}$ (i.e. mid-water level). The distribution of damage for the wave directions $-30^{\circ}$ and $0^{\circ}$ is very similar to the results for the $1: 1.5$ roundhead. For the wave direction $30^{\circ}$ the point of maximum damage is now the front segment (Segment A). The amount of displaced stones (size is approximately 10\%-15\% smaller) is comparable to the 1:1.5 roundhead. The number of stones in the armour layer of the 1:2 roundhead is however about a factor 2 higher, such that the damage ratio $N_{d}$ is approximately a factor 2 lower than for the 1:1.5 roundhead. Summarising, the results show that the distribution of damage is rather similar for the roundheads with 1:1.5 and 1:2 slopes, but the amount of damage in terms of percentage of displaced stones is significantly less (approximately a factor 2 ) for the roundhead with a 1:2 slope. 


\section{Temporary roundheads (with submerged part)}

Fig.9 shows results for the 1:1.5 temporary roundhead, again for a water depth of $0.475 \mathrm{~m}$ (i.e. mid-water level, water depth above the berm is $0.125 \mathrm{~m})$. Each panel in Fig.9 shows the damage $\left(N_{d}\right)$ per segment for one of the tested wave directions $\left(-30^{\circ}, 0^{\circ}, 30^{\circ}, 60^{\circ}\right.$ and $\left.90^{\circ}\right)$.
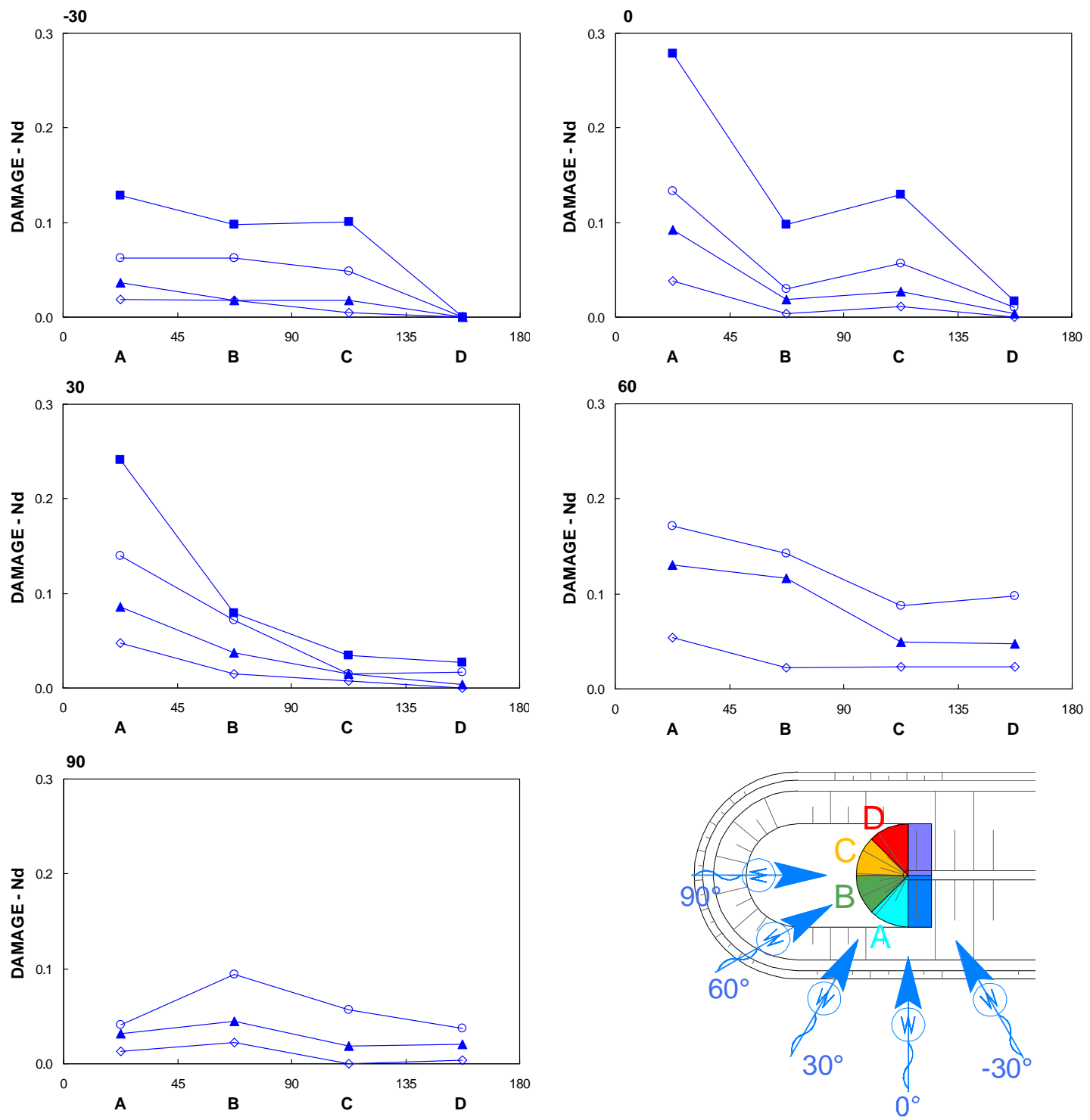

Figure 9. Damage per segment (A-D) for various wave directions $\left(-30^{\circ}, 0^{\circ}, 30^{\circ}, 60^{\circ}\right.$ and $\left.90^{\circ}\right)$ for a $1: 1.5$ temporary roundhead.

Fig.9 shows that the highest damage is observed in Segment A for directions $-30^{\circ}, 0^{\circ}, 30^{\circ}$ and $60^{\circ}$. For the tests with head-on-waves $\left(90^{\circ}\right)$ a symmetric damage would again be expected with a maximum in Segments B and C. The results show somewhat more damage in Segment B, thus not entirely symmetric. This is expected to be caused by variations of stones in the armour layer, not by variations in the wave loading (see also Fig.10).

A different result was seen for the completed roundhead. Those tests with a completed roundhead showed also relatively more damage at an angle larger than $90^{\circ}$ relative to the wave direction; this is not the case, or less pronounced, for the temporary roundhead.

Summarising, the results for the temporary roundhead indicate that there is one segment with relatively high damage, namely Segment A. 


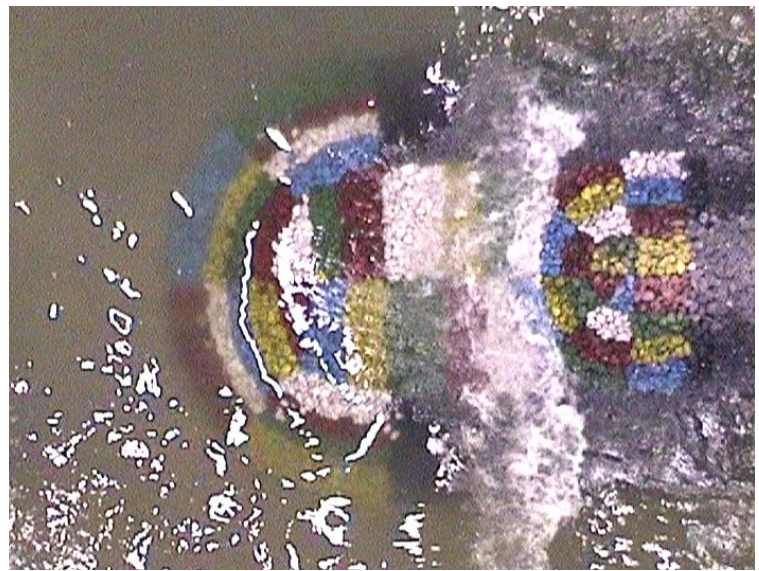

Figure 10. Picture of head-on-waves $\left(90^{\circ}\right)$ for a 1:1.5 temporary roundhead.

Fig.11 shows results for the 1:2 temporary roundhead. For each of the tested wave directions ($30^{\circ}, 0^{\circ}$ and $30^{\circ}$ ) results are again shown for a water depth of $0.475 \mathrm{~m}$ (i.e. mid-water level, water depth above the berm is $0.125 \mathrm{~m}$ ). The distribution of damage for the wave directions $0^{\circ}$ and $30^{\circ}$ is very similar to the results for the $1: 1.5$ roundhead. For the wave direction $-30^{\circ}$ the point of maximum damage is for the test with the highest wave Segment B (instead of Segment A). The amount of displaced stones (size is approximately $10 \%-15 \%$ smaller) is much higher compared to the 1:1.5 roundhead. The number of stones in the armour layer of the 1:2 roundhead is however about a factor 2 higher, such that the damage ratio $N_{d}$ is very similar.

Summarising, the results show that the distribution of damage is in general similar for the roundheads with 1:1.5 and 1:2 slopes. Also the amount of damage in terms of percentage of displaced stones is similar.
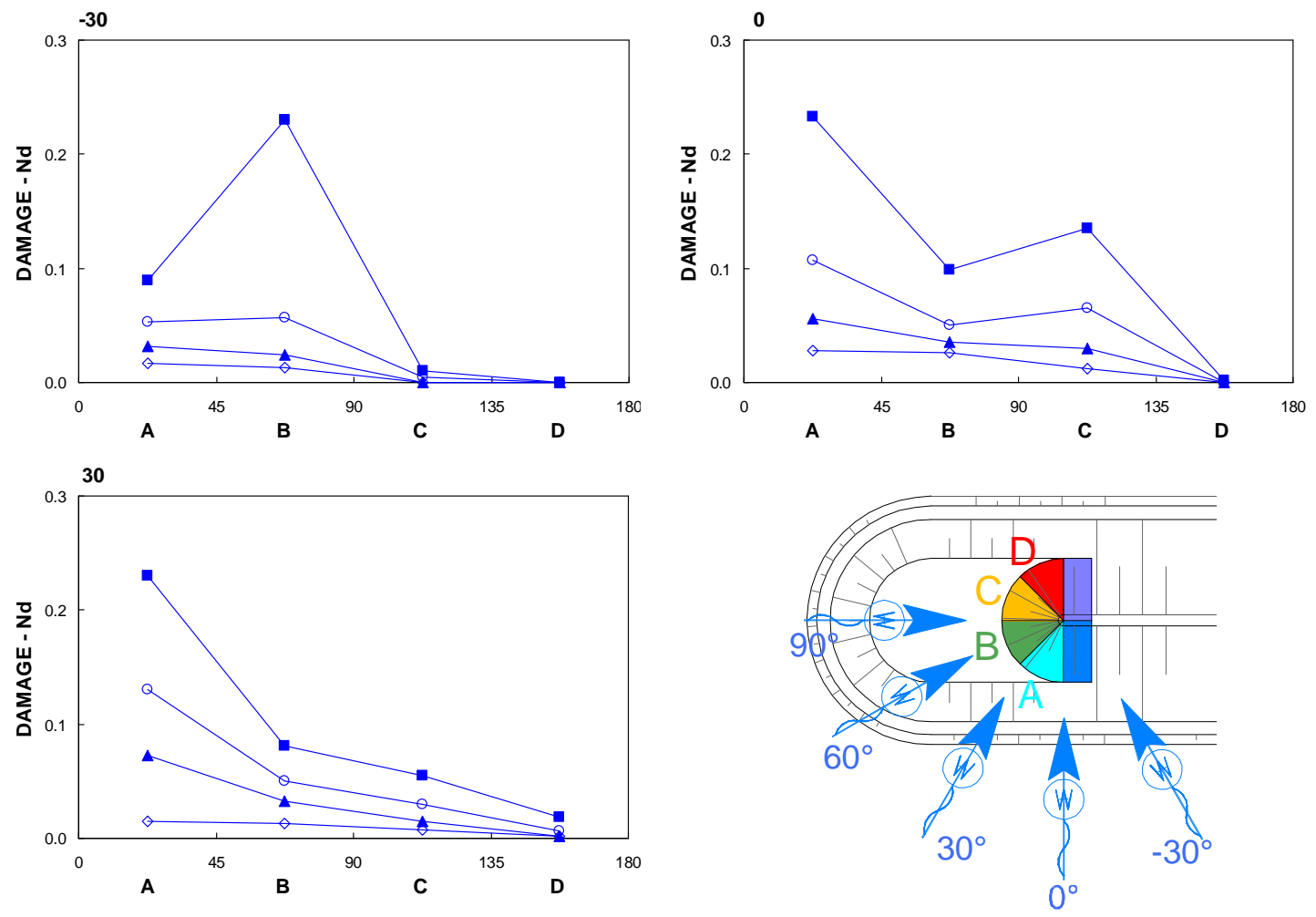

Figure 11. Damage per segment (A-D) for various wave directions $\left(-30^{\circ}, 0^{\circ}\right.$ and $\left.30^{\circ}\right)$ for a $1: 2$ temporary roundhead. 


\section{Comparisons of roundheads (with and without submerged part)}

Fig.12 shows comparisons between results obtained from tests with the 1:1.5 roundhead with and without the submerged part. Each panel in Fig.12 shows the damage $\left(N_{d}\right)$ per segment for one of the tested wave directions $\left(-30^{\circ}, 0^{\circ}, 30^{\circ}, 60^{\circ}\right.$ and $\left.90^{\circ}\right)$ for the mid-water level. In contrast to the results shown in Fig.7 for the 1:1.5 completed roundhead, now only the damage above the level of the horizontal submerged berm is taken into account. Since most of the displaced stones are displaced from the part above the level of the submerged berm the number of displaced stone is nearly the same. However, the total number of stones in the armour layer above the level of the submerged berm is of course lower than over the entire height of the structure. This means that with the same amount of displaced stones, the values of $N_{d}$ increase compared to the results obtained over the entire height of the structure. Fig.12 shows that for all tests at this water level the damage is lower for the temporary roundhead; the differences are the smallest for Segment A. For the tests with the lower water level the damage is also lower for the temporary roundhead. For the tests with the higher water level the damage is for some tests with wave direction $0^{\circ}$ higher for the temporary roundhead, with a maximum factor of 3 for $0^{\circ}$ in Segment A (note that for wave direction $-30^{\circ}$ there is no data for comparison at the lower and higher water levels).
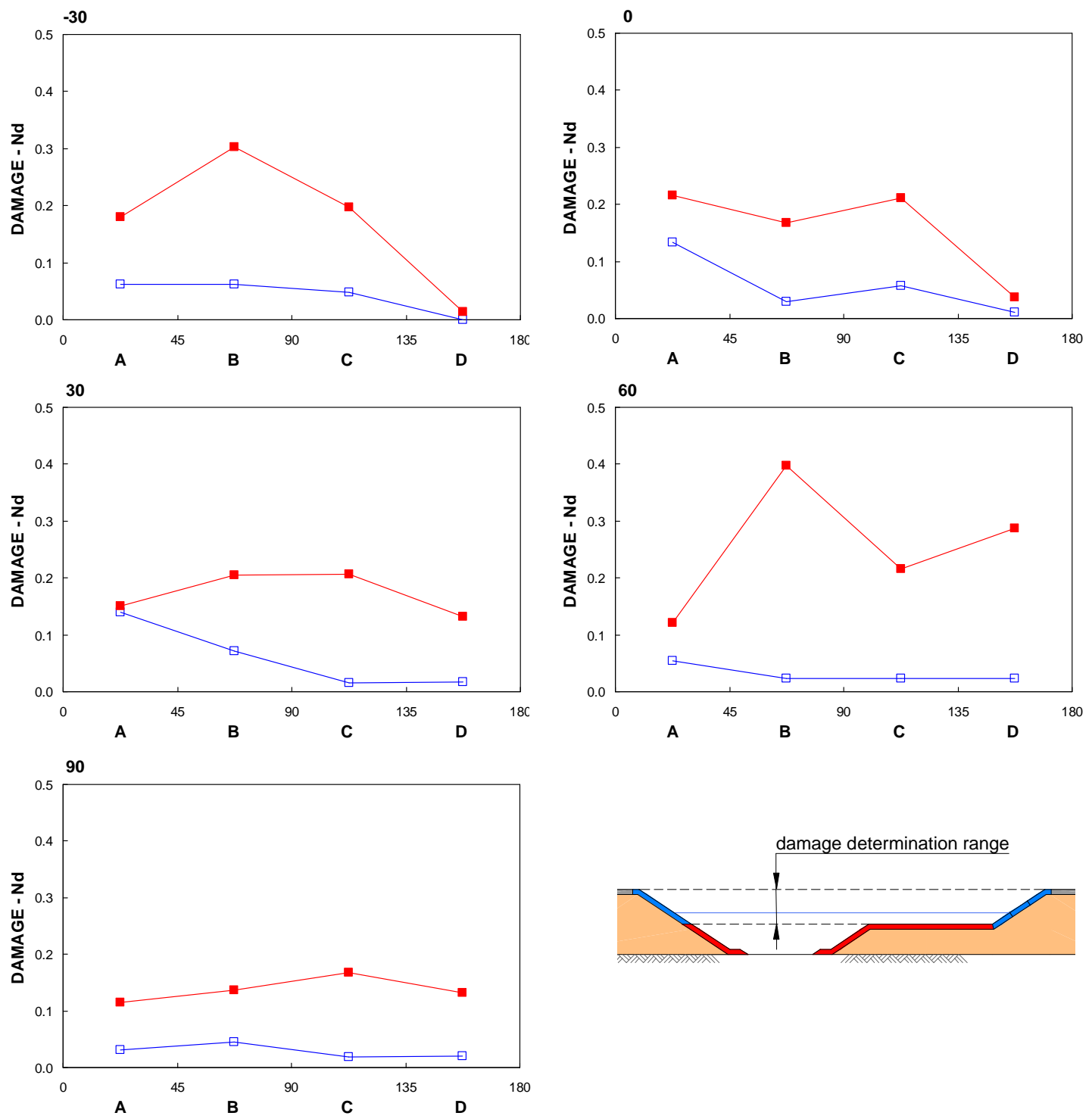

Figure 12. Comparison of damage between 1:1.5 roundheads; comparing damage above the level of the submerged berm (red filled squares denote completed roundheads, blue open squares denote temporary roundheads). 
Fig.13 shows the same comparison as shown in Fig.12, but now the entire height of the structure is taken into account for the completed roundhead. This means that the percentage of displaced stones is lower, mainly due to a larger amount of stones that is present in the armour layer. Taking this entire height of the structure into account shows that for some conditions the damage percentages are higher for the temporary roundhead, for instance in Segment A for the wave directions $-30^{\circ}, 0^{\circ}$ and $30^{\circ}$. The largest increase of damage percentage due to the submerged part is a factor of about 2.5. For the wave directions $-30^{\circ}$ and $0^{\circ}$ the distribution of damage is similar for both types of structures. For the wave directions $30^{\circ}$ and $60^{\circ}$ the distribution of damage is clearly different for both types of structures.

Fig.12 and Fig.13 show that it is essential on which part of the structure the damage percentages are based. Fig.12 provides a better impression of the differences in damage since the damage percentages are based on the same amount of stones in the armour layer.
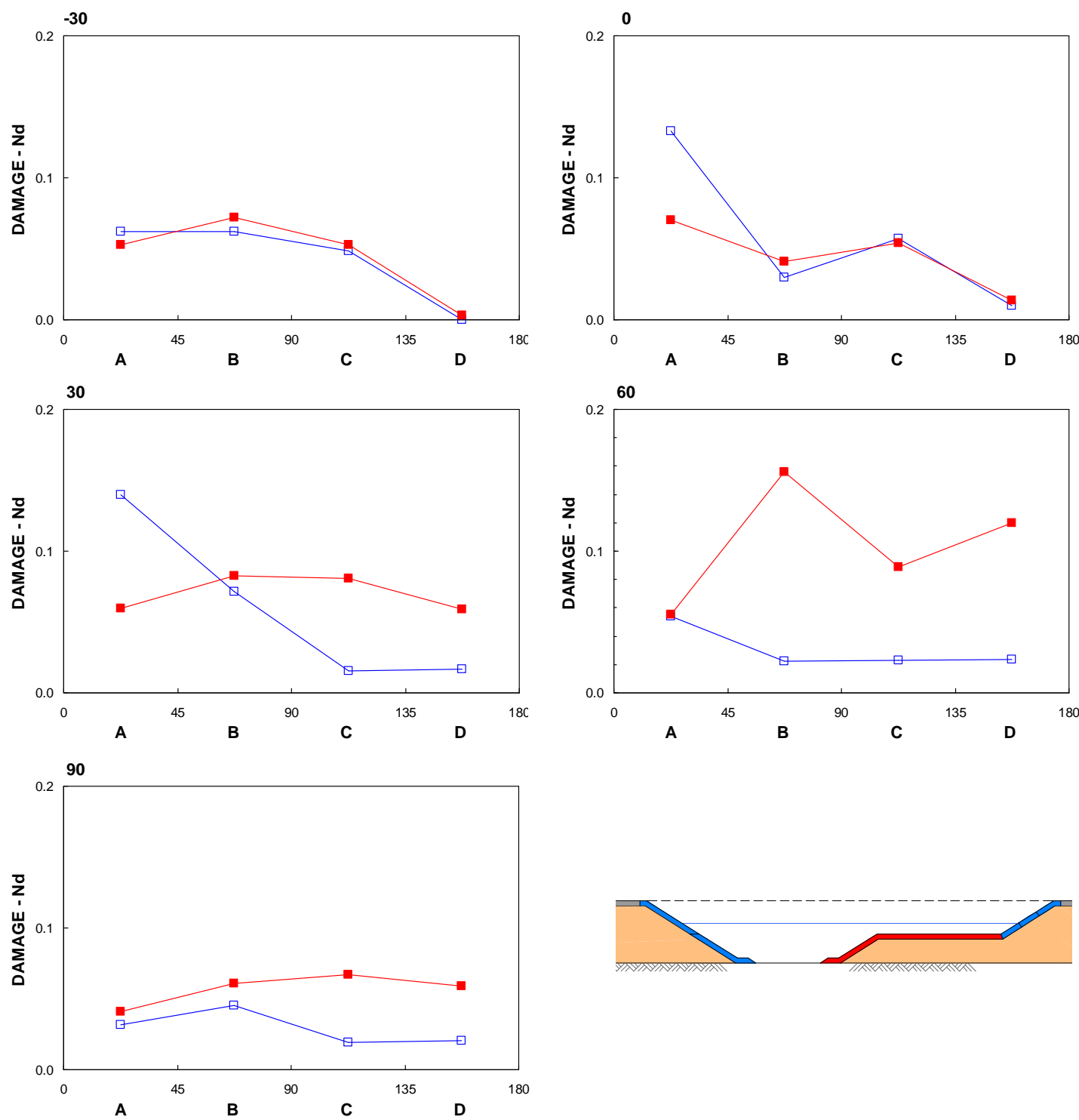

Figure 13. Comparison of damage between 1:1.5 roundheads with and without submerged part; comparing damage of the entire armour layer (red filled squares denote completed roundheads, blue open squares denote temporary roundheads). 

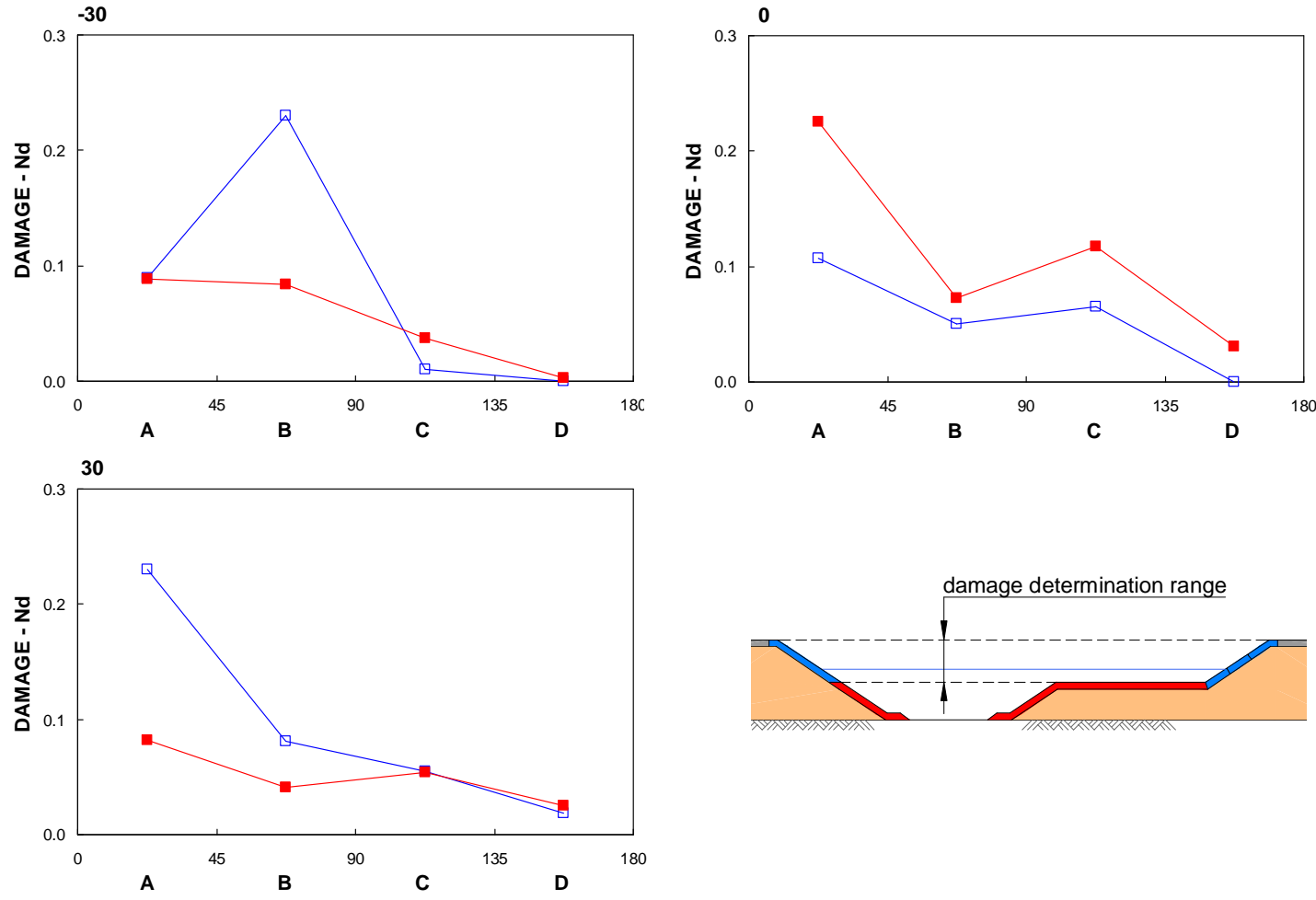

Figure 14. Comparison of damage between 1:2 roundheads with and without submerged part; comparing damage above the level of the submerged berm (red filled squares denote completed roundheads, blue open squares denote temporary roundheads).
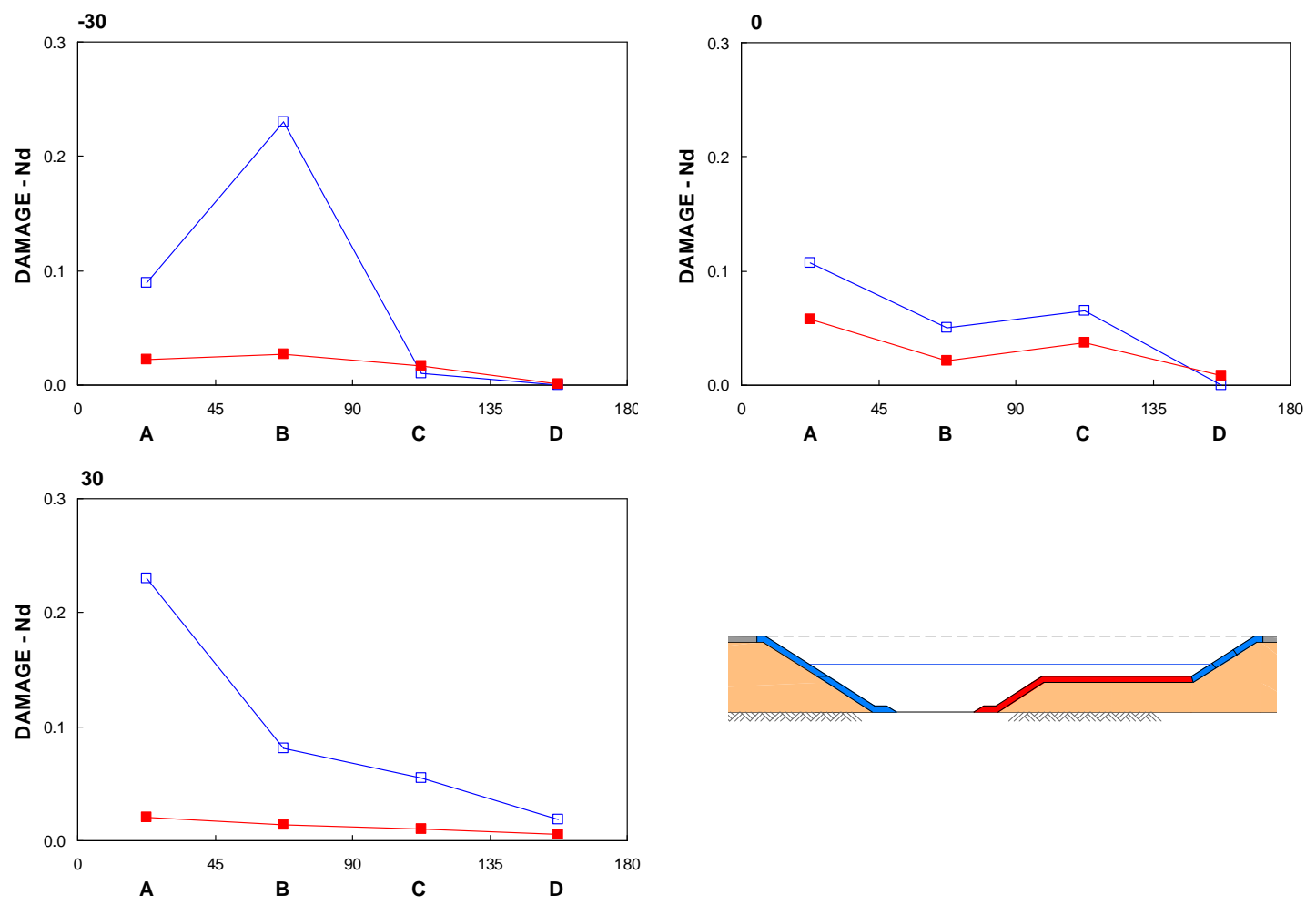

Figure 15. Comparison of damage between 1:2 roundheads with and without submerged part; comparing damage of the entire armour layer (red filled squares denote completed roundheads, blue open squares denote temporary roundheads). 
Fig.14 and Fig.15 show the comparisons between results obtained from tests with 1:2 roundheads with and without the submerged part (for wave directions $-30^{\circ}, 0^{\circ}$ and $30^{\circ}$ ) for the mid-water level (i.e. water depth above the berm is $0.125 \mathrm{~m}$ ). Fig. 14 is based on the damage above the level of the horizontal submerged berm. In Fig.15 the entire height of the structure is taken into account for completed roundhead.

Fig.14 shows that for some tests at this water level the damage is higher for the temporary roundhead; this occurs for some tests in Segments A and B $\left(-30^{\circ}\right.$ and $\left.30^{\circ}\right), e . g$. for wave direction $30^{\circ}$ a factor of about 3 was found in Segment A. Only for the wave direction $0^{\circ}$ data is available for comparisons at a lower and higher water levels; the lowest water level showed that for the wave direction $0^{\circ}$ the test with the temporary roundhead gives slightly more damage in Segment B although the differences are small.

Fig.15 shows that the damage percentages are generally higher for temporary roundheads if the entire height of the structure is taken into account for the completed roundhead. The largest increase of damage percentage due to the submerged part is about a factor 10 .

Summarizing, the results show that for the 1:1.5 structures the amount of displaced stones is lower for the temporary roundheads, with an exception in Segment A for a high water level at $0^{\circ}$ (about a factor 3 higher for the temporary roundhead). For the 1:2 structures a larger number of tests shows that in Segments A and B there are more displaced stones for the temporary roundheads (e.g. about a factor 3 higher). Using damage percentages where the entire height of the structure is taken into account for the completed roundhead instead of only above the level of the horizontal submerged berm, damage percentages can be a factor 10 higher for the temporary roundheads.

\section{Influence of water level}

The influence of the water level on the amount of damage has been studied for the structures with and without submerged part. Fig.16 shows in the upper-left panel three tests $\left(0^{\circ}\right)$ for the $1: 1.5$ structure and in the upper-right panel for the 1:2 structure. The results show that the differences are rather small, indicating that within the tested range the radius of the waterline at the roundhead (which becomes smaller with increasing water level) does not have a significant influence. In Fig.16 the ratio of the radius and $H_{s}$ was 3 to 5 for the 1:1.5 structures and 3.9 to 6.5 for the $1: 2$ structures.
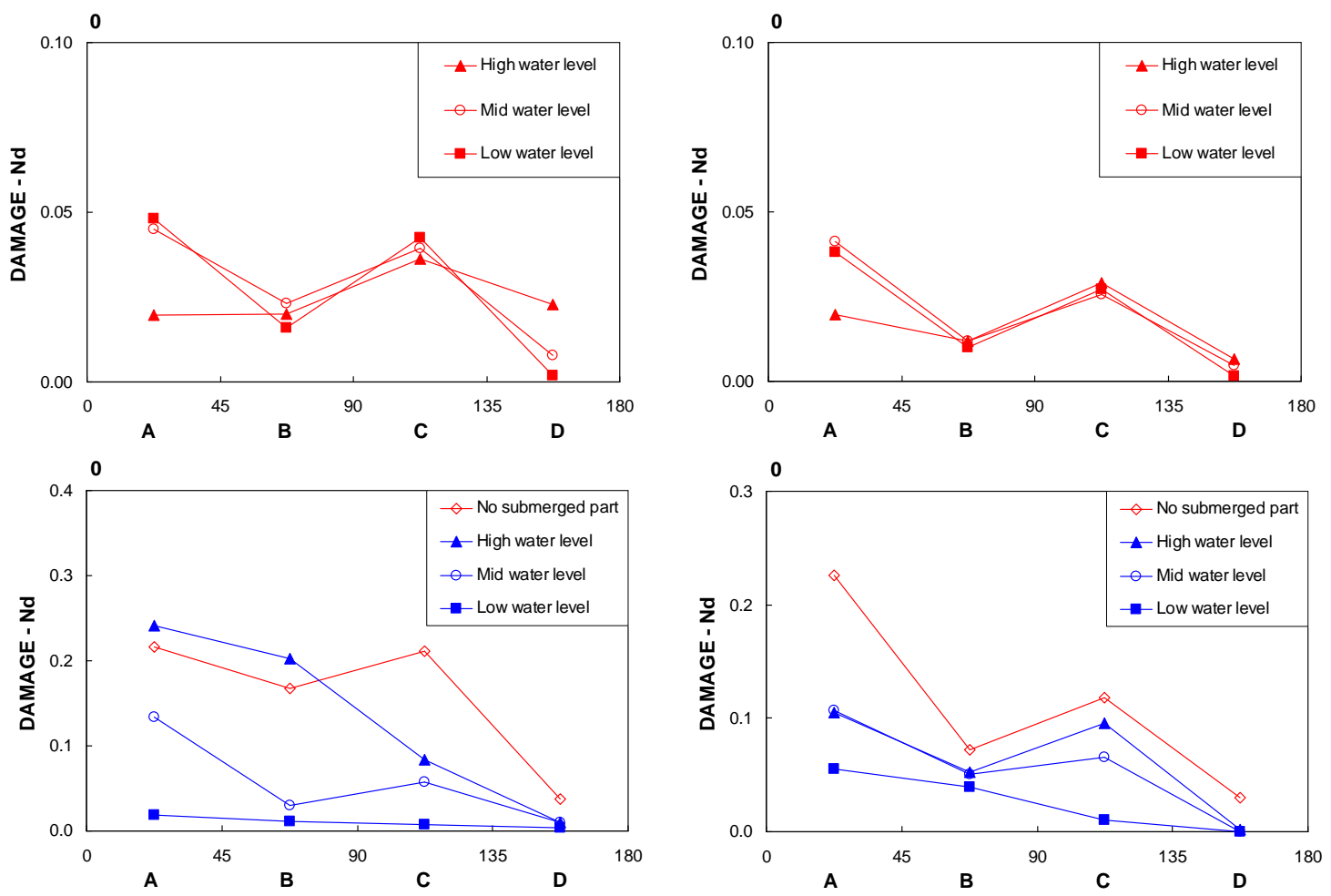

Figure 16. Influence of the water level on the damage to the 1:1.5 roundhead in left panels and a 1:2 roundhead in the right panels (wave direction $0^{\circ}$ ); upper panels denote completed roundheads. 
Fig.16 shows in the lower panels results with three water levels for the temporary roundheads and, as a reference, the results for the completed roundheads for the mid-water level (per panel the wave heights are the same), based on the stones above the level of the horizontal submerged berm only. The results show that the damage increases with increasing water level, indicating that the effect of the submerged part decreases with increasing water depth above the submerged berm; the damage tends to go upward with increasing water depth towards a damage level as if there was no submerged part.

\section{NUMERICAL MODELLING}

The test results show that many parameters play a role in the stability of roundheads. Some of the parameters have not been varied in the performed test programme (e.g. the length of the submerged part and the wave steepness) and some parameters have only been varied over a limited range. In addition to results from physical model tests it may be useful to study the influence of parameters by using a suitable numerical model. At present the state-of-the-art on numerical modelling is such that rather good numerical model simulations can be made for the wave motion. Although the wave motion can be computed, the resistance of the stones against wave motion cannot be modelled accurately. Nevertheless, a sophisticated numerical model can be applied to analyse the velocity distribution over the structure. Positions with relatively high velocities and large accelerations indicate locations with relatively severe wave loading. Using such information may provide insight into the behaviour of other structure configurations than those that have been tested in the physical model tests. For this purpose the numerical model ComFLOW has been applied. ComFLOW is a 3D VOF model based on the Navier-Stokes equations. The model has been extended with porous media flow (see Wellens et al, 2010), similar to the 2D VOF model Skylla as described in Van Gent et al (1994). To illustrate the possibilities of ComFLOW to assess information on the performance of breakwater roundheads a computation with a temporary roundhead are shown here. Although the model is capable to simulate irregular wave trains, the computation presented here has been performed with monochromatic waves $(H=0.14 \mathrm{~m}, T=1.6 \mathrm{~s}$, a porosity $n=0.4$, and Forchheimer coefficients for porous media flow based on Van Gent, 1995: $\alpha=1000$ and $\beta=1.1$ ). Fig.17 shows computed maximum velocities during a wave cycle at the structure-water interface, with waves travelling from left to right (wave direction $0^{\circ}$ ). Note the differences in colour scale between the two panels. The panel to the left focuses on the velocities at the submerged part: The red region indicates relatively high velocities due to wave breaking at the front part of the horizontal berm. The panel to the right shows the same computation, but now focussed on the emerged roundhead, showing relatively high velocities at the front of the roundhead (i.e., Segments A and B). This computation shows that this numerical model can provide insight into the area with relatively severe wave loading.

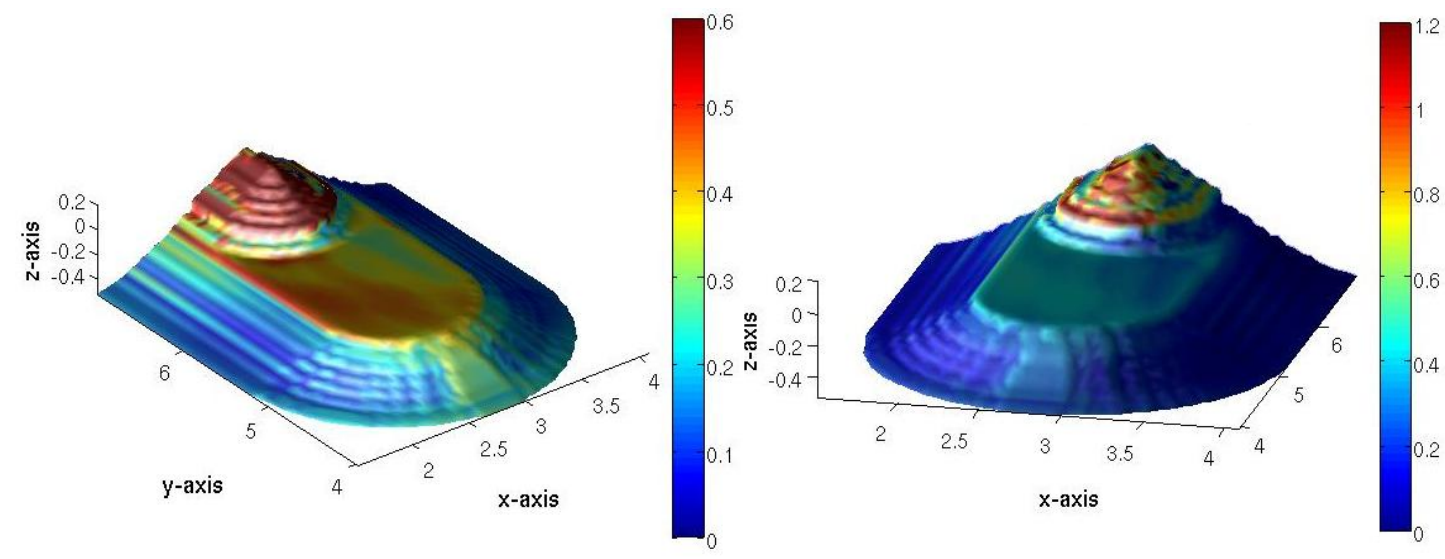

Figure 17. Computed maximum velocities $(\mathrm{m} / \mathrm{s})$ during a wave cycle at the structure-water interface, with relatively high velocities (in red) at the front of the horizontal part of the submerged berm (left panel) and at the front of the emerged part of the roundhead (right panel). 


\section{CONCLUSIONS AND RECOMMENDATIONS}

The present study focussed on the stability of the rock armour layer of rubble mound breakwater roundheads. Roundheads with and without a submerged part in front have been studied. The following conclusions have been based on the performed 3D physical model tests:

- The tests with a completed roundhead (without submerged part) show that there are two segments with more damage, namely the "front segment" (i.e., the segment with maximum wave loading; $0^{\circ}$ relative to the wave direction) and a "rear-side segment" (i.e., a segment with relatively low resistance) starting at an angle of $90^{\circ}$ relative to the wave direction.

- The tests with a completed roundhead (without submerged part) show that the distribution of damage is rather similar for the roundheads with 1:1.5 and 1:2 slopes, but the amount of damage in terms of percentage of displaced stones is significantly less (approximately a factor 2) for the roundhead with a 1:2 slope (size of stones in the 1:2 structure is approximately 10\%-15\% smaller). This is mainly due to a larger number of stones present in a 1:2 structure, not due to a different amount of displaced stones.

- The tests with a temporary roundhead (with submerged part) indicate that there is one segment with more damage, namely Segment A, which is the segment adjacent to the trunk.

- The tests with a temporary roundhead (with submerged part) show that the distribution of damage is rather similar for the roundheads with 1:1.5 and 1:2 slopes. Also the amount of damage in terms of percentage of displaced stones is similar.

- Comparisons between results for the roundheads with and without submerged part show that for the 1:1.5 structures the amount of displaced stones is generally lower for the temporary roundheads, with an exception in Segment A for a high water level and wave direction $0^{\circ}$ (about a factor 3 higher for the temporary roundheads). For the 1:2 structures a larger number of tests shows that in Segments A and B there are more displaced stones for the temporary structures (e.g. about a factor 3 higher).

- Analysing the influence of the water levels on the stability of completed roundheads, indicates that within the tested range the radius of the waterline at the structure roundhead (which becomes smaller with increasing water level) does not have a significant influence. For the temporary roundheads the results clearly show that the damage increases with increasing water level, indicating that the effect of the submerged part decreases with increasing water depth above the submerged berm; the damage tends to go upward with increasing water depth towards a damage level as if there was no submerged part.

- Numerical model computations show that the applied numerical model can provide insight into the positions on the roundhead that suffer relatively severe wave loading. The applied numerical model can, in combination with results from the performed physical model tests, provide valuable information for structure configurations that have not been tested.

Based on these findings the following recommendations are given:

- If for a roundhead the angle of the dominant incident waves is known, one may consider to apply stones with a larger weight (size and/or density) at the most vulnerable segments. For a temporary roundhead with a submerged part, this would be most appropriate in Segment A, the segment adjacent to the trunk.

- The results indicate that for some combinations of the structure slope, angle of incident waves and the water level, there is more damage at a temporary roundhead (with submerged part) than at a completed roundhead. Therefore, it is recommended to take the influence of the submerged part into account. Since the dominant waves during the construction phase are likely to be lower than those in the final situation, this does not necessarily mean that heavier material is required in the construction phase than in the final phase.

Furthermore, it is recommended to analyse whether above findings are also (partially) valid for armour layers that consist of concrete armour units rather than rock.

\section{ACKNOWLEDGEMENTS}

The assistance by colleagues from Deltares, in particular by Mr. Alberts, Mr. Coolegem, Mr. Koopmans, Mr. Pasterkamp and Mr. Scheer are greatly acknowledged. The contribution to the 
numerical model computations by Mr. Wellens from Deltares is also acknowledged. The shown interest and comments by the contractors BAM and Van Oord during the performed tests are highly appreciated.

\section{REFERENCES}

Jensen, O.J. 1984. A monograph on rubble mound breakwaters, DHI, Hørsholm.

Maciñeira, E. and H.F. Burcharth. 2008. Spatial damage distribution over cube armoured roundheads, Proc. ICCE 2008, World Scientific, Vol.4. pp.3449-3460.

Matsumi, Y., E.P.D. Mansard and J. Rutledge. 1994. Influence of wave directionality on stability of breakwater heads, Proc. ICCE 1994, ASCE, Vol.2., pp.1397-1411.

Matsumi, Y., A. Kimura and K. Ohno. 1996. Velocity field measurements over breakwater heads under 3D waves, Proc. ICCE 1996, ASCE, Vol.2., pp.1776-1788.

Matsumi, Y., A. Kimura and K. Ohno. 1998. Wave kinematics on breakwater heads and stability or armour layers under multidirectional waves, Proc. ICCE 1998, ASCE, Vol.2., pp.1906-1919.

Matsumi, Y., A. Kimura and K. Ohno. 2000. Stability of armour units on breakwater heads under multidirectional waves, Proc. ICCE 2000, ASCE, Vol.3., pp.1946-1958.

Vidal. C, M.A. Losada and R. Medina. 1991. Stability of mound breakwater's head and trunk, J. of Waterway, Port, Coastal and Ocean Engrg, ASCE, Vol. 177, No.6 Nov/Dec, pp.570-587.

Van Gent, M.R.A., P. Tönjes, H.A.H. Petit and P. van den Bosch. 1994. Wave action on and in permeable structures, Proc. ICCE 1994, ASCE, Vol.2, pp.1739-1753.

Van Gent, M.R.A. 1995. Porous flow through rubble mound material, J. of Waterway, Port, Coastal and Ocean Engineering, Vol.121, no.3, pp.176-181, ASCE, New York, by M.R.A. van Gent.

Wellens, P.R., M.J.A. Borsboom and M.R.A. van Gent. 2010. 3D modelling of wave interaction with permeable coastal structures, Proc. ICCE 2010.

Wolters, G. and M.R.A. van Gent. 2010. Oblique wave attack on cube and rock armoured rubble mound breakwaters, Proc. ICCE 2010. 